\title{
Extrapolation of mortality in COVID-19: Exploring the role of age, sex, co-morbidities and health-care related occupation
}

\author{
Shahir Asfahan, Kunal Deokar, Naveen Dutt, Ram Niwas, Priyank Jain, Mehul Agarwal \\ Department of Pulmonary Medicine, All India Institute of Medical Sciences, Jodhpur, India
}

\begin{abstract}
We used a publicly available data of 44,672 patients reported by China's centre for disease control to study the role of age, sex, co-morbidities and health-care related occupation on COVID-19 mortality. The data is in the form of absolute numbers and proportions. Using the percentages, retrospective synthetic data of 100 survivors and 100 deaths were generated using random number libraries so that proportions of ages, genders, co-morbidities, and occupations were constant as in the original data. Logistic regression of the four predictor factors of age, sex, co-morbidities and occupation revealed that only age and comorbidities significantly affected mortality. Sex and occupation when adjusted for other factors in the equation were not significant predictors of mortality. Age and presence of co-morbidities correlated negatively with survival with co-efficient of -1.23 and -2.33 respectively. Odds ratio (OR) for dying from COVID-19 for every 10-year increase in age was 3.4 compared to the previous band of 10 years. OR for
\end{abstract}

Correspondence: Kunal Deokar, Department of Pulmonary Medicine, All India Institute of Medical Sciences, Jodhpur, Rajasthan, India. Email: dkunal@live.in

Key words: COVID-19; mortality; determinants.

Conflicts of interest: The authors declare that they have no competing interests, and all authors confirm accuracy.

Authors' contributions: All the authors are responsible for the concept, design and definition of the work. All the authors have read and approved the final version of the manuscript and agreed to be accountable for all aspects of the work.

Ethics committee approval: Obtained.

Availability of data and materials: All data generated or analyzed during this study are included in this published article.

Received for publication: 18 April 2020.

Accepted for publication: 18 May 2020.

${ }^{\circ}$ Copyright: the Author(s), 2020

Licensee PAGEPress, Italy

Monaldi Archives for Chest Disease 2020; 90:1325

doi: 10.4081/monaldi.2020.1325

This article is distributed under the terms of the Creative Commons Attribution Noncommercial License (by-nc 4.0) which permits any noncommercial use, distribution, and reproduction in any medium, provided the original author(s) and source are credited. dying of COVID-19 was 10.3 for presence of any of the co-morbidities. Our findings could help in triaging the patients in emergency room and emphasize the need to protect elderly and those with comorbidities from getting exposed.

\section{Introduction}

COVID-19 pandemic is raging across the world peaking in one nation after another. It is happening in the digital era with almost real time updates from across the world. Despite this unique advantage of ease of information sharing, yet no anonymised dataset of individual patients has been released in the public domain for research or tailoring of responses or application of artificial intelligence to generate models to predict the outcomes.

Generating and learning from own country's data is not a luxury at present as healthcare systems have been known to be overwhelmed even in first world countries. Hence, we had to resort to extrapolation of data from a publicly available data of 44,672 patients reported by China's centre for disease control. This dataset included information of survivors and deaths along with proportion of age, sex, occupation and comorbidities [1].

Although the general directions of age and co-morbidities with respect to COVID-19 mortality are known, the strength of association have not been elucidated to the best of our knowledge and are pertinent for policy making and building effective responses.

\section{Materials and Methods}

Data of 44,672 patients of whom there were 1023 deaths has been released in the public domain by China's Centre for Disease Control with details on age groups, gender, co-morbidities, and occupations under creative commons license. The data are in the form of absolute numbers and proportions. Using the percentages, retrospective synthetic data of 100 survivors and 100 deaths were generated using random number libraries so that proportions of ages, genders, co-morbidities, and occupations were constant as in the original data.

Logistic regression was performed on the dataset using ages, genders, co-morbidities and occupation as predictor variables in relation to outcome of survival or death. Backward elimination of predictor variables was done removing the variables with p-value $>0.05$ till we were left with variables having a significant $p$-value $(<0.05)$. Odd's ratio $(\mathrm{OR})$ for mortality was computed from the coefficients of logarithmic equation. Generation of data and statistical analysis was done in Python 3.6. 


\section{Results}

Base-line characteristics of the sample data are shown in Table 1 . Most of the mortality $(81 \%)$ was in the ages above 60 years. There was a preponderance of males (63.8\%) among those who died. Occupations listed were those working in service industry, farmer/labourer, health worker, retiree and rest were classified as others. As retiree would naturally correlate with older age group, this was merged in those classified as others which made up for the bulk of the group. Co-morbid conditions listed were hypertension, diabetes, cardiovascular disease, cancer and rest were classified as belonging to 'none' category. Hypertension followed by cardiovascular disease and diabetes were the predominant co-morbidities in that order; $32.8 \%$ of the deaths occurred in those without any co-morbidities. Table 2 shows the encodings for various categories.

Logistic regression of the four predictor factors of age, sex, comorbidities and occupation revealed that only age and comorbidities significantly affected mortality. Sex and occupation when adjusted for other factors in the equation were not significant predictors of mortality. Effects of age, sex, co-morbidities and occupation are shown in Figures 1-4. Age and presence of co-morbidities correlated negatively with survival with co-efficient of -1.23 and -2.33 respectively. Odds ratio (OR) for dying from COVID-19 for every 10-year increase in age was 3.4 compared to the previous band of 10 years. OR for dying of COVID-19 was 10.3 for presence of any of the comorbidities listed. Surface plot of the association between age, sex and outcome (death or survival) is shown in Figure 5.

Table 1. Baseline demographics of the original dataset. Co-morbidities were only available for 20,812 patients and percentages listed below were calculated accordingly.

\begin{tabular}{|c|c|c|c|}
\hline Baseline characteristics & Survived, n (\%) & Deaths, n (\%) & Case fatality rate, $\%$ \\
\hline Overall & 43,649 & 1023 & 2.3 \\
\hline $\begin{array}{l}\text { Age, years } \\
0-9 \\
10-19 \\
20-29 \\
30-39 \\
40-49 \\
50-59 \\
60-69 \\
70-79 \\
\geq 80\end{array}$ & $\begin{array}{c}416(0.95) \\
548(1.25) \\
3612(8.27) \\
7582(17.37) \\
8553(19.54) \\
9878(22.63) \\
8274(18.95) \\
3606(8.26) \\
1200(2.74)\end{array}$ & $\begin{array}{c}- \\
1(0.1) \\
7(0.7) \\
18(1.8) \\
38(3.7) \\
130(12.7) \\
309(30.2) \\
312(30.5) \\
208(20.3)\end{array}$ & $\begin{array}{c}- \\
0.2 \\
0.2 \\
0.2 \\
0.4 \\
1.3 \\
3.6 \\
8.0 \\
14.8\end{array}$ \\
\hline $\begin{array}{l}\text { Sex } \\
\text { Male } \\
\text { Female }\end{array}$ & $\begin{array}{l}22,328(51.15) \\
21,321(48.84)\end{array}$ & $\begin{array}{l}653(63.8) \\
370(36.2)\end{array}$ & $\begin{array}{l}2.8 \\
1.7\end{array}$ \\
\hline $\begin{array}{l}\text { Occupation } \\
\text { Service industry } \\
\text { Farmer/labourer } \\
\text { Health worker } \\
\text { Other/none }\end{array}$ & $\begin{array}{c}3426(7.84) \\
9672(22.15) \\
1711(3.91) \\
28,840(66.07)\end{array}$ & $\begin{array}{c}23(2.2) \\
139(13.6) \\
5(0.5) \\
856(83.6)\end{array}$ & $\begin{array}{l}0.7 \\
1.4 \\
0.3 \\
2.9\end{array}$ \\
\hline $\begin{array}{l}\text { Comorbid condition } \\
\text { Hypertension } \\
\text { Diabetes } \\
\text { Cardiovascular disease } \\
\text { Chronic respiratory disease } \\
\text { Cancer (any) } \\
\text { None } \\
\end{array}$ & $\begin{array}{c}20,308 \\
2522(12.41) \\
1022(5.03) \\
781(3.84) \\
479(2.35) \\
101(0.49) \\
15,403(75.84) \\
\end{array}$ & $\begin{array}{c}504 \\
161(39.7) \\
80(19.7) \\
92(22.7) \\
32(7.9) \\
6(1.5) \\
133(32.8)\end{array}$ & $\begin{array}{c}6.0 \\
7.3 \\
10.5 \\
6.3 \\
5.6 \\
0.9 \\
\end{array}$ \\
\hline
\end{tabular}

Table 2. Data encoding done for the purpose of building the logistic regression.

\begin{tabular}{|c|c|c|c|c|c|c|c|c|}
\hline Codes & 0 & 1 & 2 & 3 & 4 & 5 & 6 & 7 \\
\hline $\begin{array}{l}\text { Age } \\
>80\end{array}$ & $0-9$ & $10-19$ & $20-29$ & $30-39$ & $40-49$ & $50-59$ & $60-69$ & $70-79$ \\
\hline Gender & Male & Female & & & & & & \\
\hline Co-morbidities & Hypertension & Diabetes & Cardiovascular disease & Chronic respiratory disease & Cancer & None & & \\
\hline Occupation & Service industry & Farmer/Labourer & Health Worker & Other & & & & \\
\hline
\end{tabular}




\section{Discussion}

We tried to study the factors affecting mortality in COVID-19 patients. As our own institutional data set was not available due to early stage of the disease, we used the data of 44,672 COVID-19 patients reported by China's Centre for disease control (CDC) [1].

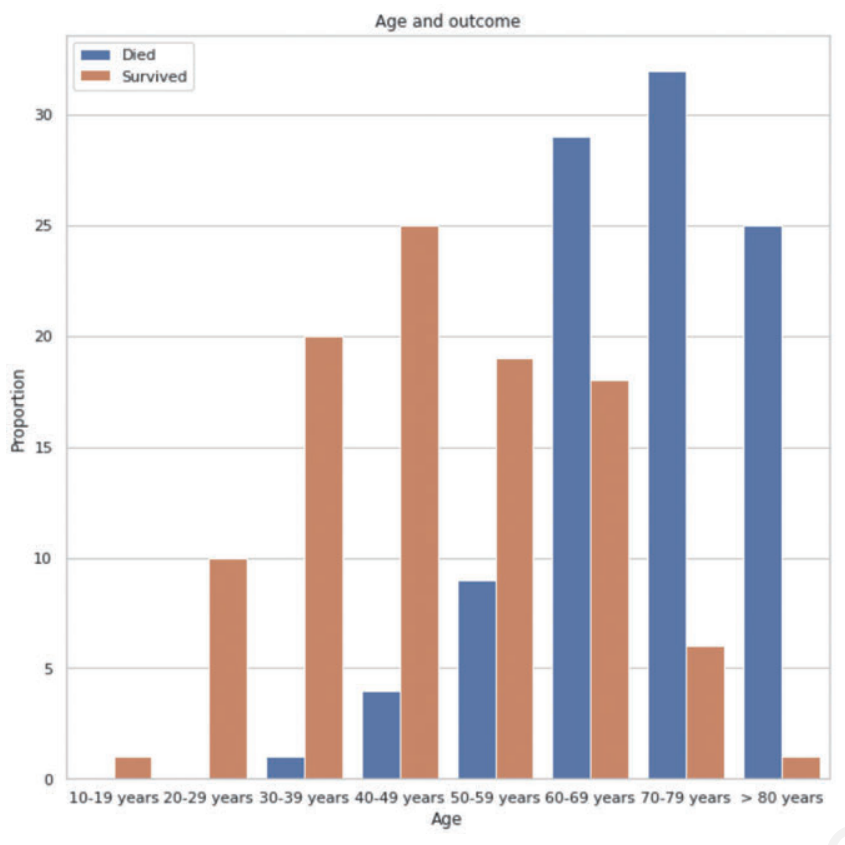

Figure 1. Bar diagram showing distribution of age among survivors and non-survivors.

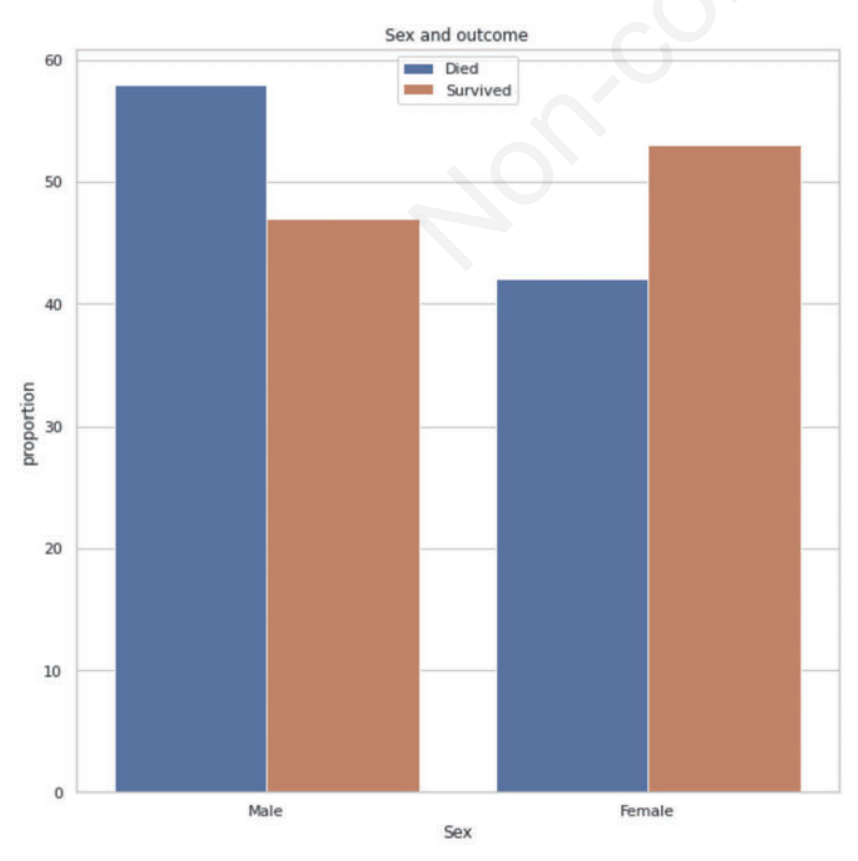

Figure 2. Bar diagram showing distribution of sex amongst survivors and non-survivors.
Age was an important risk factor for mortality. Age correlated negatively with survival with a coefficient of -1.23 . Mortality increased with advancing age. $81 \%$ of deaths were in patients above the age of 60 years. The odds ratio of mortality from COVID-19 increased by 3.4 times for every 10 years increase in age $(\mathrm{p}=0.00)$. In a retrospective study by Ruan et al., there was a significant difference in age between death group and discharge

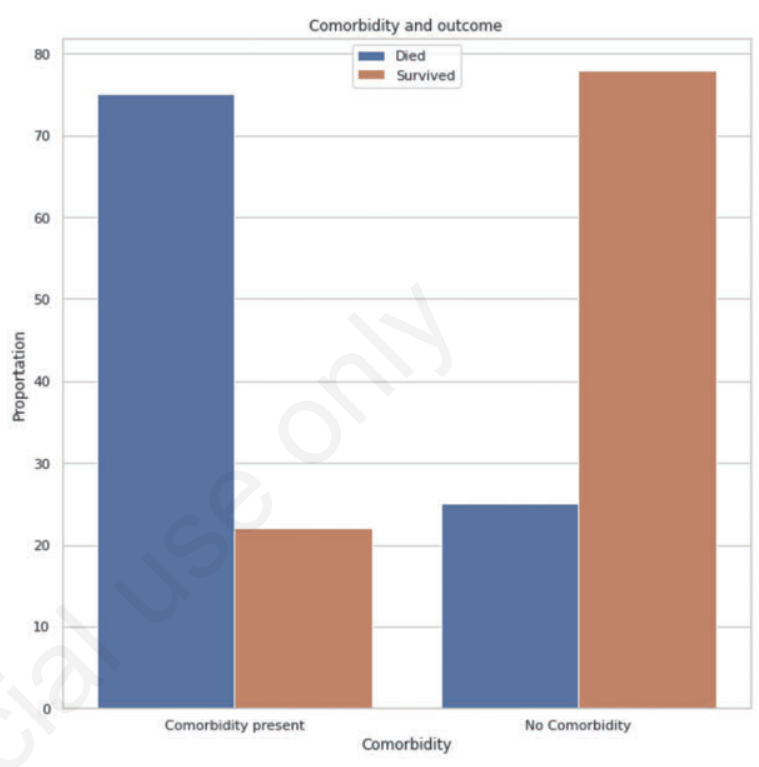

Figure 3. Bar diagram showing distribution of comorbidities amongst survivors and non-survivors.

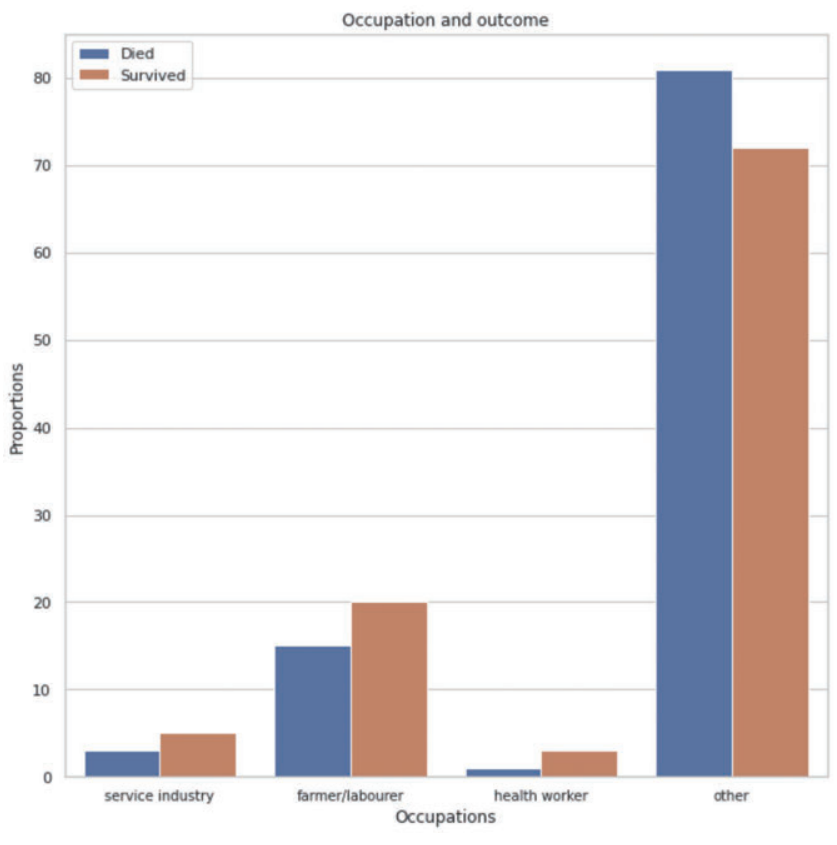

Figure 4. Bar diagram showing distribution of occupation among survivors and non-survivors. 
group $(p<0.001)$ [2]. In their study, mortality increased with increase in age. Zhou et al. in a retrospective study, analysed data of 191 laboratory confirmed COVID -19 cases and found that older age was associated with increased odds of death (OR 1.13; $\mathrm{p}=0.0043$ ) [3]. Advanced age has been shown to be an independent predictor of mortality even in SARS [4] and MERS-CoV [5] infections. Age dependent decline in cell mediated and humoral immunity with a Th2 skewed response may be responsible for increased mortality in elderly [6].

Presence of any comorbidity like hypertension, diabetes mellitus, cardiovascular disease, chronic respiratory disease and cancer significantly affected the mortality. Patients with any of the comorbidities listed in the reported dataset had 10.3 times higher odds of death due to COVID-19 as compared to those without any comorbidity $(\mathrm{p}=0.00)$. In a meta-analysis by Yang et al, which included eight studies with 46,248 patients, authors found that the pooled odds ratio of hypertension, respiratory system disease, cardiovascular disease in severe patients as compared to non-severe patients were $2.36,2.46$ and 3.426 respectively [7]. In another metanalysis by Li et al., which included six studies with 1527 patients, comorbidities like hypertension, cardio-cerebrovascular diseases, and diabetes were more common in severe patients [8]. In a retrospective single center case series, Guo et al. observed that patients with underlying cardiovascular diseases and other co-morbidities had higher incidence of myocardial injury. These patients with co-morbidities who developed myocardial injury had higher mortality [9]. Presence of comorbidities was also associated with poor outcomes in SARS [10] and MERS-CoV infections [11]. There is limited data describing the relationship between effect of co-morbidities on mortality.

As per our analysis, there was no significant effect of sex and occupation on mortality. Similar results were also observed by Zhou et al in their retrospective cohort of 191 patients [3]. Though it appears that mortality was more in males (Males 63.8\%; Females
$36.2 \%$ ) in our dataset, after controlling for other variables using multivariate logistic regression, sex and occupation were found to have no significant effect ( $\mathrm{p}>0.05$ for both) on mortality.

We acknowledge a few limitations of our study. These figures were derived from a reverse randomised generation of the largest reported data till date and may be susceptible to some variation from the true estimate.

Our study is unique in that it has assessed the odds for mortality for every incremental increase in age of 10 years, thereby quantifying the risk for most age groups which has not been addressed in any other study till date. Though previous studies $[7,8]$ showed that presence of co-morbidities is associated with increased severity of illness, they did not assess for its strength in relation to mortality, which was addressed by the present study. We believe that armed with this information, policy makers will be able to appropriately categorize the risk of each individual in those diagnosed with COVID-19 as well as those caring for them.

\section{Conclusions}

Age and co-morbidities are the two main determinants of mortality in COVID-19. Odds of mortality increase by 3.4 times for every 10 -year increase in age and 10.3 times for presence of any major co-morbidity.

These findings could help in allocation of scarce resources at areas of greatest needs like allotment of ICU beds to triaging in the emergency room . It also highlights the need for older healthcare workers to be removed from areas of excessive risk for infection to more administrative positions and to let the younger and healthier health-care workers be more involved in the caring of COVID-19 patients.

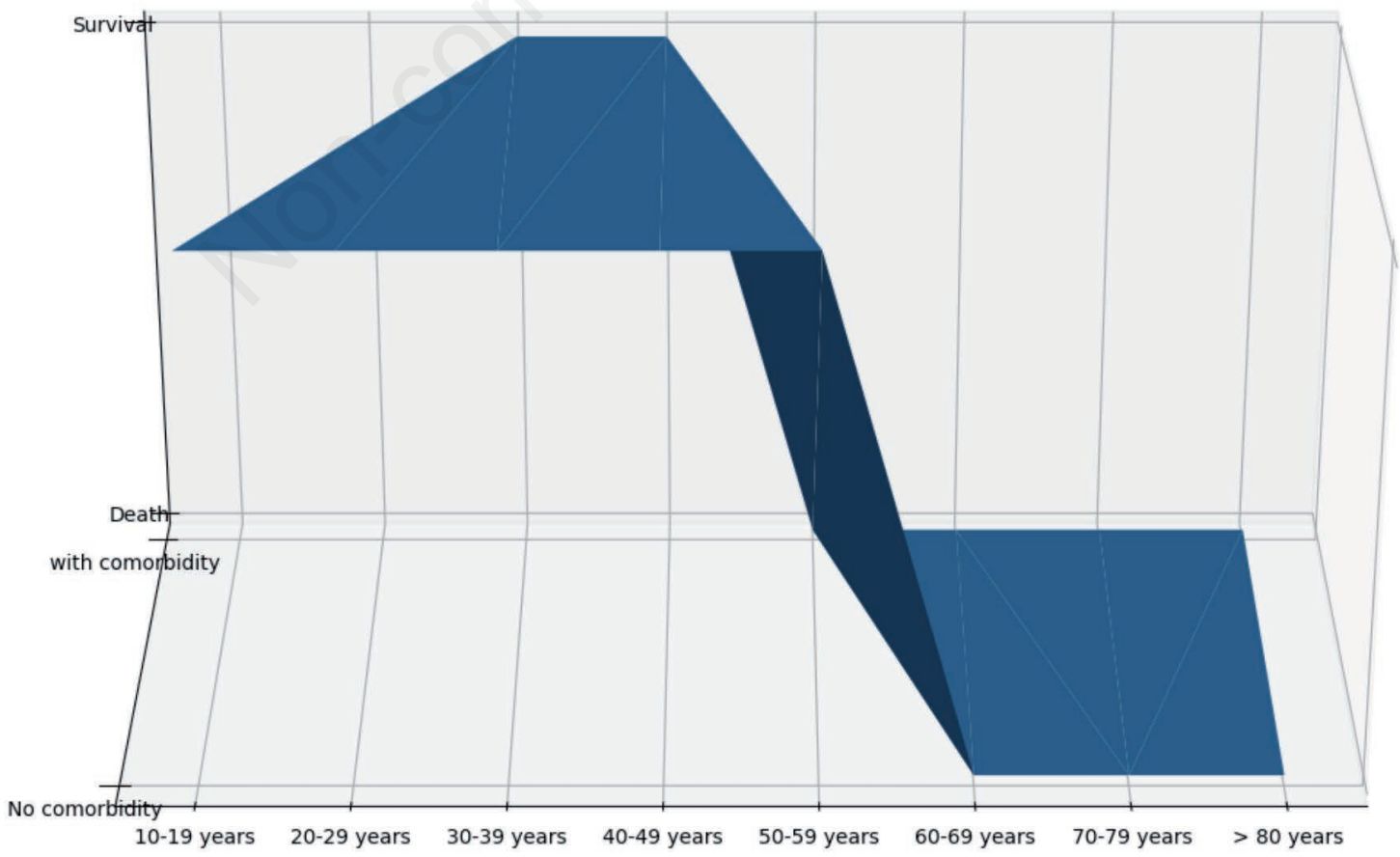

Figure 5. 3D-Surface plot displaying the relationship between age, comorbidity and outcome. Older age and presence of comorbidity was associated with mortality 
Also we suggest that in view of various levels of lockdowns being implemented across the world, that even when the lockdowns are eased, the senior citizens and those with co-morbidities need to be protected from getting exposed while the virus moves in the population towards achieving herd immunity.

\section{References}

1. Novel Coronavirus Pneumonia Emergency Response Epidemiology Team. Vital surveillances: the epidemiological characteristics of an outbreak of 2019 novel coronavirus diseases (COVID-19) - China, 2020. China CDC Weekly. Accessed on: 9 April 2020. Available from: http://weekly.chinacdc.cn/en/ article/id/e53946e2-c6c4-41e9-9a9b-fea8db1a8f51

2. Ruan Q, Yang K, Wang W, et al. Clinical predictors of mortality due to COVID-19 based on an analysis of data of 150 patients from Wuhan, China. Intensive Care Med 2020. doi: 10.1007/s00134-020-05991-x.

3. Zhou F, Yu T, Du R, et al. Clinical course and risk factors for mortality of adult inpatients with COVID-19 in Wuhan, China: a retrospective cohort study. Lancet 2020. doi: 10.1016/s01406736(20)30566-3.

4. Choi KW, Chau TN, Tsang O, et al. Outcomes and prognostic factors in 267 patients with severe acute respiratory syndrome in Hong Kong. Ann Intern Med 2003;139:715-23.

5. Hong K-H, Choi J-P, Hong S-H, et al. Predictors of mortality in Middle East respiratory syndrome (MERS). Thorax 2018;73:286-9.

6. Opal SM, Girard TD, Ely EW. The immunopathogenesis of sepsis in elderly patients. Clin Infect Dis 2005;41:S504-12.

7. Yang J, Zheng Y, Gou X, et al. Prevalence of comorbidities in the novel Wuhan coronavirus (COVID-19) infection: a systematic review and meta-analysis. Int J Infect Dis 2020;94:91-5. doi: 10.1016/j.ijid.2020.03.017.

8. Li B, Yang J, Zhao F, et al. Prevalence and impact of cardiovascular metabolic diseases on COVID-19 in China. Clin Res Cardiol 2020;109:531-8.

9. Guo T, Fan Y, Chen M, et al. Cardiovascular implications of fatal outcomes of patients with coronavirus disease 2019 (COVID-19). JAMA Cardiol 2020;e201017. doi: 10.1001/ jamacardio.2020.1017.

10. Booth CM, Matukas LM, Tomlinson GA, et al. Clinical features and short-term outcomes of 144 patients with SARS in the greater Toronto area. JAMA 2003;289:2801-9.

11. Matsuyama R, Nishiura H, Kutsuna S, et al. Clinical determinants of the severity of Middle East respiratory syndrome (MERS): a systematic review and meta-analysis. BMC Public Health 2016;16:1203. 